\title{
Acute myocardial infarction not attributed to coronary artery disease: a seldom initial presentation of a left ventricular myxoma.
}

Kyriakos Spiliopoulos ${ }^{1}$, Zacharias Anyfantakis ${ }^{1}$, Ilias Diminikos ${ }^{1}$, Andrew Xanthopoulos ${ }^{1}$, Dimitrios Magouliotis ${ }^{1}$, John Skoularigis ${ }^{1}$, and Filippos Triposkiadis ${ }^{1}$

${ }^{1}$ University of Thessaly School of Health Sciences

August 4, 2020

\begin{abstract}
Although myxoma represents the most frequent non-malignant cardiac primary tumor; it is extremely rare met in the left ventricle. Clinical features of the neoplasm extend from symptomless to critical signs of either ischemia or embolism. We describe a case of a huge left ventricular myxoma presented with acute myocardial infarction.
\end{abstract}

\section{Hosted file}

myxomarevision2.doc available at https://authorea.com/users/348739/articles/473938-acutemyocardial-infarction-not-attributed-to-coronary-artery-disease-a-seldom-initialpresentation-of-a-left-ventricular-myxoma

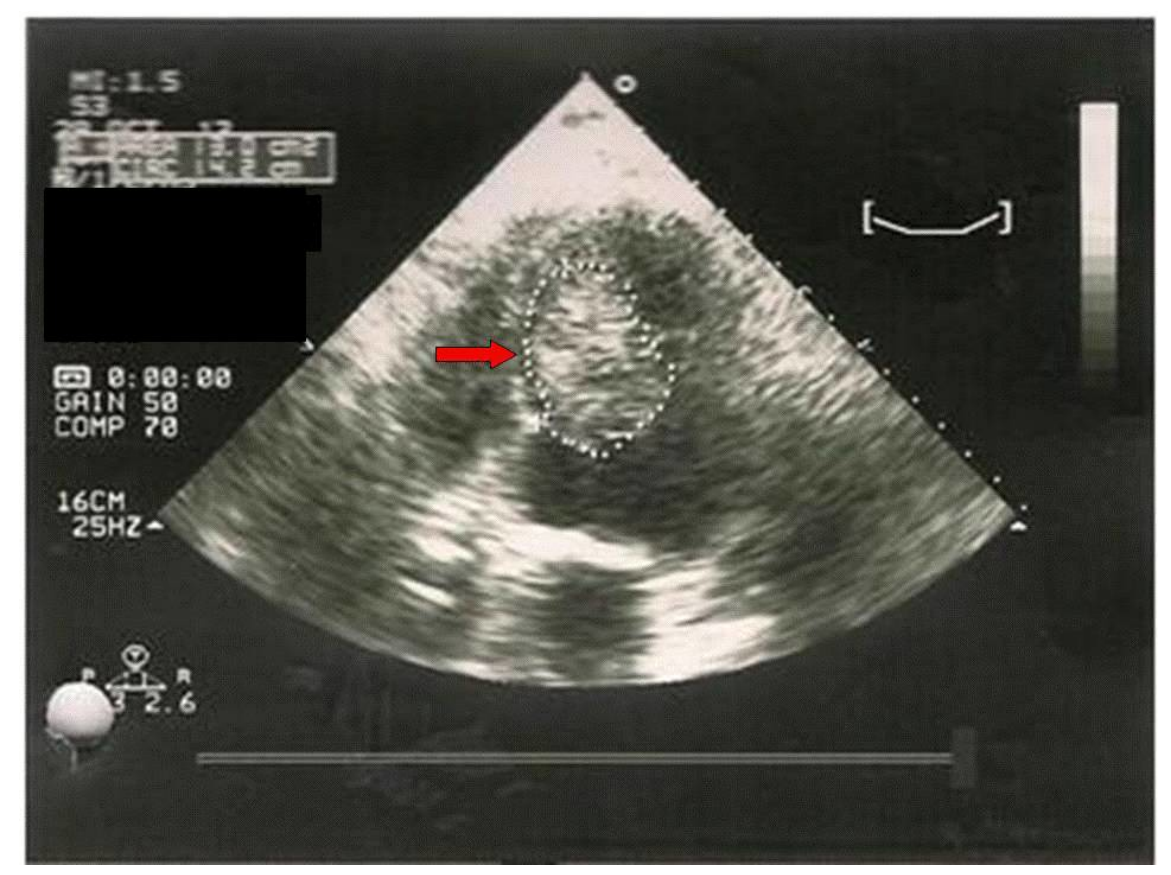



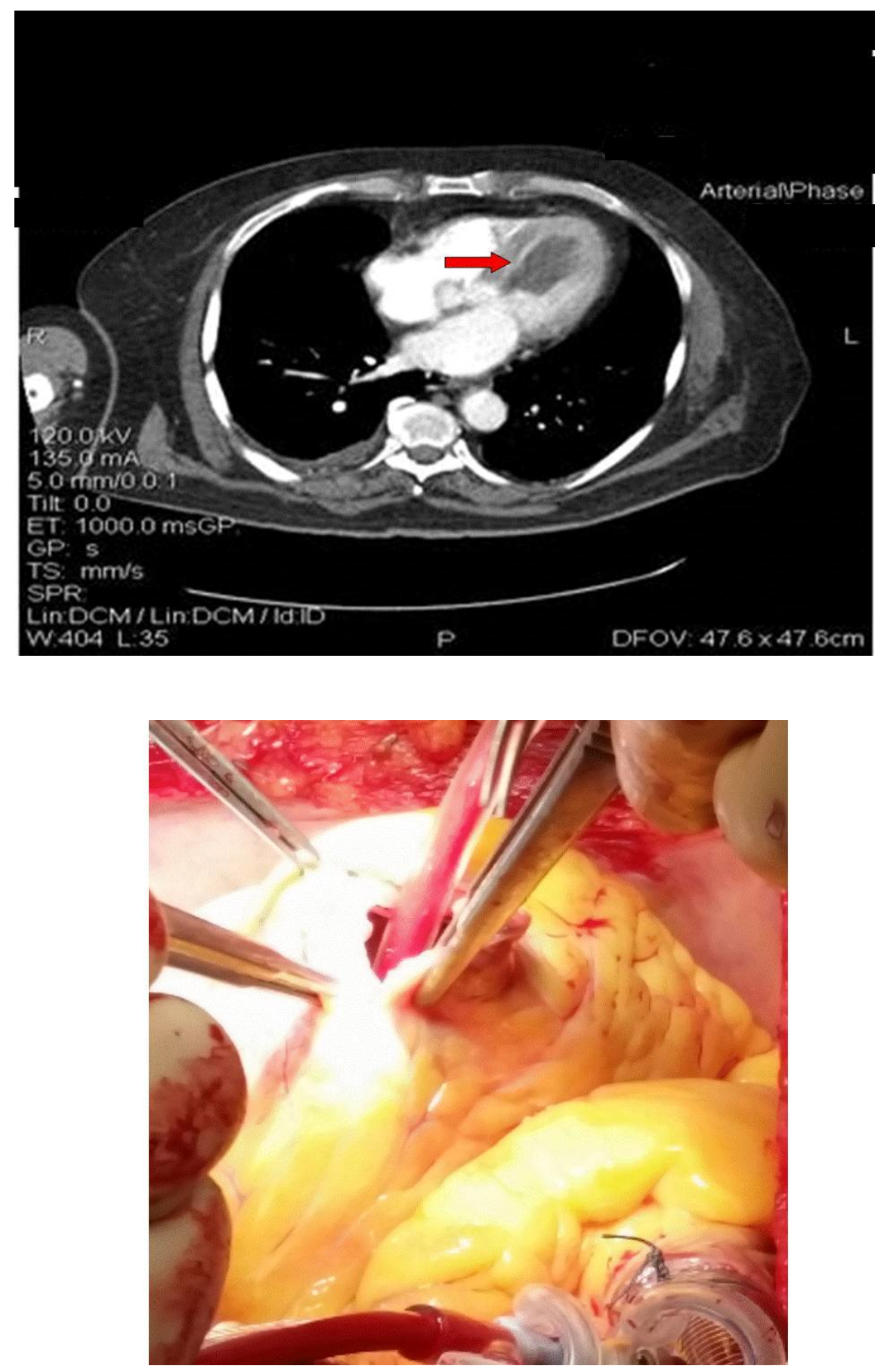